\title{
Non-phosphorylating alternative respiratory pathways are involved in an increase of wheat resistance to heat stress
}

Fedotova O.A. ${ }^{1}$, Polyakova E.A. ${ }^{1,2 *}$, Grabelnych O.I. ${ }^{1,2}$

${ }^{1}$ Siberian Institute of Plant Physiology and Biochemistry, SB RAS, Irkutsk, Russia

${ }^{2}$ Irkutsk State University, Irkutsk, Russia

*email: polyackova.elizaveta727@yandex.ru

The non-phosphorylating alternative pathways of plant mitochondria are presented by the alternative cyanide-resistant oxidase (AOX) and rotenone-insensitive internal (NDA) and external (NDB) type II NAD(P)H dehydrogenases (NAD(P)H-DH). The physiological significance of these respiratory pathways is actively studied. Regulation of alternative pathways occurs both at the levels of gene expression and posttranslationally and strongly depend on the physiological state of the plant and growth conditions.

The influence of heat treatments on the heat stress tolerance of spring wheat (Triticum aestivum L.) and its relation with the alternative pathways, content of water-soluble carbohydrates in leaves, content of ROS, and regulation of the production of ROS by alternative respiratory pathways were determined.

Heat treatment $\left(39^{\circ} \mathrm{C}\right.$ for $\left.24 \mathrm{~h}\right)$ led to an increase in the heat resistance of wheat and the accumulation of water-soluble carbohydrates. AOX, NDA, NDB were activated by heat treatment and its activation was also high after the subsequent influence of heat stress $\left(50{ }^{\circ} \mathrm{C}\right.$ for $\left.3 \mathrm{~h}\right)$. The content of AOX protein isoforms depended on the intensity and duration of heat treatments. Heat treatments $\left(37\right.$ and $\left.39^{\circ} \mathrm{C}\right)$ revealed the increased AOX contribution and high rate of NADH oxidation. In addition, the content of AOX protein depends on the wheat development phase under high temperatures. Heat treatment reduced mitochondrial peroxide level, but the subsequent influence of heat stress led to its increase. The antioxidant function of AOX was revealed. However, this function is not the main at high temperatures in photosynthetic plants. Moreover, slight increase of peroxide was noted upon inhibition of complex I of the respiratory chain during heat treatment, which may indicate a possible role of $\mathrm{NAD}(\mathrm{P}) \mathrm{H}-\mathrm{DH}$ in the formation of ROS. Thus, the data obtained indicates the important role of alternative respiratory pathways in the adaptation of wheat to high temperatures.

Acknowledgments: This work is supported by the grant of the President of the Russian Federation (MK-1720.2020.4). 